\title{
Plotting Academic Innovation: A Content Analysis of Twenty Institutional Websites
}

\author{
Adam P. Barger ${ }^{1}$ D $\cdot$ Kelly Govain Leffel $^{1}$ (D) $\cdot$ Mia Lott $^{1}$
}

Accepted: 17 June 2021 / Published online: 29 July 2021

(c) The Author(s), under exclusive licence to Springer Nature B.V. 2021, corrected publication 2022

\begin{abstract}
Academic innovation is an increasingly integrated effort and focus area in higher education institutions. Academic innovation units often include multiple foci, such as teaching and learning research, faculty development programming, and entrepreneurial elements. However, there is a lack of consensus on what defines successful academic innovation or how best to contextualize innovation efforts within a particular university environment. This content analysis of 20 university academic innovation websites explored the varied approaches, programming, and communication pathways of academic innovation as revealed through publicly available website content. Findings suggest varied levels of academic innovation impact along with common tensions regarding innovation effort versus efficacy. Additionally, the analysis surfaced challenges in communicating innovation successes across internal and external audiences.
\end{abstract}

Keywords Academic innovation · Educational technology · Faculty development · Teaching and learning

Academic innovation at higher education institutions (HEIs) is quickly becoming a mainstream feature of faculty development, teaching and learning programming, and entrepreneurial ventures. Forays into innovative areas such as adaptive learning, pedagogical partnerships, technology enhancements, and multimodal learning often aspire to create successful responses to evolving learning environments (Blumenstyk \& Gardner, 2019). However, there is little consensus on what constitutes academic innovation or what indicates successful academic innovation processes (Findlow, 2008; Tierney \& Lanford, 2016; Whitworth, 2011). As HEIs consider what works in their own university environments, they contextualize academic innovation through various programming options and initiatives to create their own

Adam P. Barger

apbarger@wm.edu

1 The Studio for Teaching \& Learning Innovation, William \& Mary, 100 Ukrop Way, William \& Mary, Morton 111, Williamsburg, VA 23187, USA 
operational definitions of academic innovation as well as indicators of success. This presents higher education faculty and administrators with the challenge of plotting a path towards academic innovation that has little or no comparative evaluation. Additionally, underlying elements of educational technology often overlap with academic innovation efforts, further blurring the lines between teaching and learning with technology and more specific aspects of innovation (e.g., King \& Boyatt, 2014). Finally, the communities of stakeholders involved with academic innovation seem inconsistent across HEI contexts even though stakeholders are often instrumental in evaluating innovation success (Whitworth, 2011). A better understanding of academic innovation across various institutions provides higher education leaders with insights on both academic innovation goals and processes.

Exploring common communication features of HEI academic innovation units, such as websites, provides an aerial view of academic innovation in multiple contexts and formats. This article reports on a content analysis of academic innovation websites undertaken to better understand the approaches, programming, and communication pathways of academic innovation. The study was designed to explore the potential commonalities, discrepancies, and challenges across 20 institutions. After a review of relevant literature, we focused the inquiry in the areas of educational technology, academic innovation evaluation, and community connectedness. The following research questions guided our approach and analysis:

1. How, if at all, is academic innovation linked to educational technology?

2. What standards of evaluation for successful academic innovation are most evident?

3. What stakeholder communities exist for implementing meaningful connections with academic innovation processes?

These research questions situate our exploration within academic innovation as a trending area of emphasis in HEIs. We explored academic innovation processes and related website communication rather than overall perceived change. These parameters served to anchor our understanding within academic innovation initiatives specifically without attempting to capture institutional change processes broadly. Though there is an appetite for finding and scaling innovations for change in higher education (Kezar, 2011), we situate this analysis within the forward-facing communication and community processes of academic innovation across a range of institutional contexts. In doing so, we aim to contribute a complementary understanding of academic innovation as a bespoke and often highly visible effort in higher education.

The following sections detail the literature base, methodological approach, analysis, and discussion of academic innovation as communicated through institutional websites. First, we explore extant literature organized by the aforementioned areas of inquiry. Second, we address content analysis methods and specific aspects of analyzing hypertext. Then, we detail our findings structured by code frequency counts to illuminate significant content types and infer relationships 
across themes (Krippendorff, 2013). We apply Serdyukov's (2017) levels of innovation impact as an interpretive construct to help describe the potential degree of impact as communicated by academic innovation activity on institutional websites. Finally, we discuss ongoing challenges and tensions with academic innovation as an aspect of universities' programming and forward-facing communication.

\section{Literature Review}

Definitions of academic innovation in related literature differ widely due to varied conceptual assumptions and institutional contexts. Though many scholars and higher education professionals agree the term innovation is a buzzword and susceptible to disparate approaches and applications, academic innovation is generally viewed as a posture of responsiveness, or reflexivity, to the many changes in the higher education environment (Blumenstyk \& Gardner, 2019). Related characteristics of newness, novelty, and creativity are often associated with academic innovation as a concept rather than a strictly defined approach or process (Serdyukov, 2017; Tierney \& Lanford, 2016). Academic innovation processes are frequently characterized similarly to general innovation pathways for new services and workflows or implementing new ideas (Kezar, 2011; Stvilia \& Gibradze, 2019). These descriptions differ from more change-oriented descriptions of innovation as a result of transformational learning or the need for institutional change (e.g., Kezar et al., 2018). Some extant research points to innovation as natural iterative processes responding to the evolving higher education landscape (Hoffman \& Holzhuter, 2012; Tierney \& Lanford, 2016). Therefore, a useful baseline definition for academic innovation is the conception and application of new or novel ideas in evolving learning environments. However, the process of how best to respond to higher education trends and the specific challenges prompting a desire for academic innovation are up for debate.

\section{Academic Innovation and Educational Technology}

Academic innovation research and popular writing often present an overlap with educational technology, digital innovations, or eLearning in general. According to Serdyukov (2017), innovation in education includes both a novel idea and a successful change resulting from the implementation of that idea. Serdyukov found innovations in education often focused on productivity and efficiency of learning, both fitting sparks for technology use. Similarly, Whitworth (2011) case study of a significant technology-based classroom innovation found that technology-based innovations are both risky and attractive in that the promise of successful change is tempered by the potential for perceived failure or embarrassment of stakeholders. In this way, educational technology as a pathway to academic innovation is hard to strategically manage (King \& Boyatt, 2014). Given the tendency to view technology as a new or novel approach to an unmet need, it is natural for HEIs to favor technocentric innovations in programs and initiatives (Papert, 1987, 1988). 
Several researchers address this blurred line between academic innovation and educational technology, though they differ in their assessment of specific differences between the two foci. Stvilia and Gibradze (2019) cited technology in the top 12 service categories revealed through analysis of social media communications across 36 HEI innovation centers. However, they note eight other service categories ranked ahead of technology that may or may not include technology use in implementation (e.g. community building, operations, networking). Similarly, King and Boyatt (2014) described eLearning as a HEI workplace innovation that supports teaching and learning efforts across faculty, staff, and administrative roles. Their case study revealed eLearning uptake as a phenomenon interrelated with at-large innovation efforts, such as institutional strategy or learning communities, to centrally integrate eLearning tools and resources. These institutional contextual realities become more complex when the higher education landscape is considered as part of an increasingly technological workforce and a knowledge-driven economy.

Academic innovation through educational technology is partially fueled by an increasingly diverse student body preparing for a more technology-driven economy (Dobbins, 2009). As instructors and students alike play a role in the adoption of new educational technology applications, the continuum of what counts as innovation ranges from mere adjustments in the educational process to full transformation of the educational system (Serdyukov, 2017). The higher education environment is notoriously static (Lindquist, 1974) and, until recently, inherently resistant to innovation in any sense, including technology. A fuller understanding of how, if at all, academic innovation tracks separately from educational technology is partially found in the standards of evaluation emerging from HEI innovation initiatives.

\section{Standards of Evaluation for Academic Innovation}

Success in academic innovation initiatives is not often defined clearly or closely aligned with specific desired outcomes. There is general consensus that unclear success standards are a long-standing symptom of the larger problem of HEI politics, culture, and general agency or authority of stakeholders such as faculty and administrators (Jakovljevic, 2018; Lindquist, 1974; Whitworth, 2011). However, a more targeted concept emerging from extant literature is the pathway for evaluation. Beyond exploring what success looks like in academic innovation, HEIs must answer the question of what approach to take when evaluating academic innovation efforts. It is relatively easy to deem an innovation successful based simply on participation and/or completion of a project. It is much more challenging to determine and apply standards of evaluation across multiple initiatives (Findlow, 2008). Such an effort requires attention to both contextualizing standards of evaluation and communicating successes to the appropriate stakeholders.

Academic innovation, framed as new or novel ideas in evolving learning environments, is inherently context-bound within unique institutional environments. Learning environments are multifaceted information ecologies containing unique stakeholders, institutional factors, and curricular contexts (Barger, 2016). As a result, contextualized standards of evaluation for academic innovation are shaped by the 
many characteristics of HEIs such as mission, values, revenue goals, and student needs. Whitworth (2011) found conflicting assessments of innovation success or failure depending on what stakeholders were involved with generating the innovation initiative. When innovations emerge, they are likely to be "judged against criteria of success or failure which are themselves negotiated (Cervero \& Wilson, 1998), a process likely to be influenced by institutional stakeholders who can bring capital to bear" (Whitworth, 2011, p. 147). This tension complicates both the process of innovative efforts and the buy-in of the internal community (Findlow, 2008). Moreover, Jakovljevic (2018) reported an important dualism in HEI innovation: stakeholder buy-in to an innovation culture at HEIs does not necessarily lead to innovation. Actualizing innovation and determining success must be both collective and individual processes with consistent and centralized indicators of success (Jakovljevic, 2018; Tierney \& Lanford, 2016). However, these processes, if they exist, are inexorably linked to communication of academic innovation within the community and HEIs more broadly.

Outcomes of an academic innovation initiative are typically communicated in favorable terms to better situate innovation stakeholders as part of an HEI's culture. Innovation communication examples focusing on stakeholders, rather than processes or outcomes, are found in pedagogical innovation (Walder, 2017), technological innovation (Whitworth, 2011), and curricular innovation (Dobbins, 2009). In each case, the presence of academic innovation initiatives are in and of themselves communicated as successful. Though communication about success standards are not ignored entirely, they are most often framed in terms of specific individuals or communities that were closely involved. An examination of the role of stakeholder communities in academic innovation reveals the significance of sponsorship and buy-in when HEIs position themselves as innovators.

\section{Stakeholder Communities in Academic Innovation}

Academic innovation in HEIs often encounters the traditional loosely coupled system found in many educational organizations (Orton \& Weick, 1990; Weick, 1976). Intersecting systems of instructors, students, administrators, and staff provide both rich opportunities to innovate in multiple areas and the challenge of recruiting interest and buy-in for the academic innovation process (Serdyukov, 2017). A change or need in one group of stakeholders may trigger innovation in another. For example, Dobbins (2009) found student body diversity and the changing workforce to be important factors in engaging faculty and staff in conversations and sharing sessions around innovation. Similarly, administrators often point to innovations as a way to be nimble and responsive to change on an institutional level (Blumenstyk $\&$ Gardner, 2019). These varying perspectives result in different starting points and methods for academic innovation.

Stakeholders internal to HEI academic innovation often include students, faculty, and/or administrators, each with important perspectives and feedback pathways (Blumenstyk \& Gardner, 2019). Students are primary customers of HEI academic innovation and often stand to benefit the most from successful initiatives. However, 
this primacy of student experience can backfire in that students' quality of experience is affected by secondary considerations such as funding, long-term viability, and adoption rate of student-centric innovations (Findlow, 2008). Similarly, faculty members are often incorporated into academic innovation efforts to help deliver or administer pedagogical innovations or experiential learning interventions. Here, too, faculty can experience disconnects between the intended innovation and its effect on the larger learning community (Blumenstyk \& Gardner, 2019). For example, Walder's (2017) grounded analysis found most instructors' perceptions of pedagogical innovations were positive, whether or not students perceived the same positive effect on learning. Administrators aiming to find broad consensus and encourage collaboration across the university must work to promote buy-in despite these potential disconnects. As noted by Tierney and Lanford (2016), stakeholders in an innovative environment must strive for open communication and transparency while responding to the entrepreneurial or market demands of the modern university.

Stakeholders external to HEI academic innovation may include other universities, donors or investors, and the general public (McClure, 2015). These groups have varying degrees of involvement in specific academic innovation initiatives while still carrying weight in terms of institutional ratings and public opinion (Tierney \& Lanford, 2016). The desire of HEIs to present innovative successes and positive publicity is natural and important to most institutions' missions. However, academic innovation often operates within a teaching and learning frame, which may not attract the published assets or public attention of more entrepreneurial or trailblazing university efforts (Whitworth, 2011). For these reasons, the popular communications methods of websites, digital newsletters, and other online resources become key components of community building in academic innovation and, as such, are worthy of further investigation and analysis. The present study leveraged publicly available HEI academic innovation websites to structure a content analysis exploring links to educational technology, academic innovation success standards, and stakeholder communities.

\section{Methods}

This study examined hypertext and associated content on institutional websites to reveal the communication, approach, and programming of academic innovation. We employed content analysis methods to facilitate systematic readings of text coupled with interpretive analysis (Krippendorff, 2013). Content analysis of web-based content is increasingly used to explore readily available content via quantitative and qualitative approaches (Kim \& Kuljis, 2010). Challenges inherent to analyzing webbased content include unstable or changing texts, a limited unit of analysis, and sampling of texts in multiple modalities such as images, words, and animations (Kim \& Kuljis, 2010; McMillan, 2000).

To meet these challenges, we identified our sample, unit of analysis, and coding approach across several in-person research sessions to strengthen interrater reliability and shared understanding of the content. We began by identifying twenty institutional sites through Google search terms related to academic 
innovation in HEIs. We did not limit our search to certain types of institutions (ie. private or public) or schools of a certain size that might indicate varying levels of funding. Instead, our criteria for vetting sites included a specific focus on academic or teaching and learning innovation rather than primarily entrepreneurial ventures (see Table 1). In doing so, our sampling method employed purposeful strategies with an emphasis on specific criterion anchored in a synthesis of the literature (Palinkas et al., 2015; Patton, 2002; Suri, 2011). For example, some HEIs that were identified in our initial search and seemed to fit our criteria, but upon further inspection, focused more on information technology support, rather than academic innovation. These institutions were eliminated from further analysis.

Based on Krippendorff's (2013) approach to unitizing, we determined a definable unit to be the institution's academic innovation main pages and one level, or click, down from each menu item. For example, if a main web page included a menu item about programs, we followed that item to the next level to explore the programs. This approach is consistent with recent research on click behavior and link prioritization (Song et al., 2019). We captured discrete items on each page in definable chunks such as a short paragraph, caption, or introductory sentence before an image. All data were stored, memoed, and coded in a digital qualitative web-based software that allowed for shared use and collaborative annotation.

A subset of two sites were coded and discussed to strengthen intercoder reliability through resolving differences in unitizing and coding. We leveraged a combination of a priori and open coding to organize our approach while allowing for new ideas to emerge. A priori codes aligned to the literature review themes related to educational technology, standards of evaluation, and community connections. Open coding led to multiple child codes to further indicate similarities and differences across sites. Data memoing, visible to all coders, provided an additional avenue for general observations and insights that informed the interpretive analysis detailed below.

As with all qualitative research, several analytical boundaries limited our approach. This study sought to analyze and interpret data in a specific context. Accordingly, study limitations include point-in-time data generation, a relatively small sample size, and a limited scope of units of analysis. Furthermore, during data analysis in April 2020, the team noticed a shift in content highlighted on the main page of the websites due to the response to COVID-19. There was a clear focus on educational technology, specifically how to support students and faculty in remote learning. While many of these institutions may have had the infrastructure to provide this kind of support prior to COVID-19, it may have been situated beyond our one-click level of analysis. Similarly, some schools may not have provided resources specific to remote learning in the past, but were quickly adapting. Our research does not focus on this reactive shift, but rather the calculated approach to academic innovation that was presented prior to the pandemic. Though generalization of findings to other study contexts is not our aim, we believe this study illuminates the specific context of academic innovation in selected HEIs and provides new avenues for understanding the situated realities and communication pathways for academic innovation. 


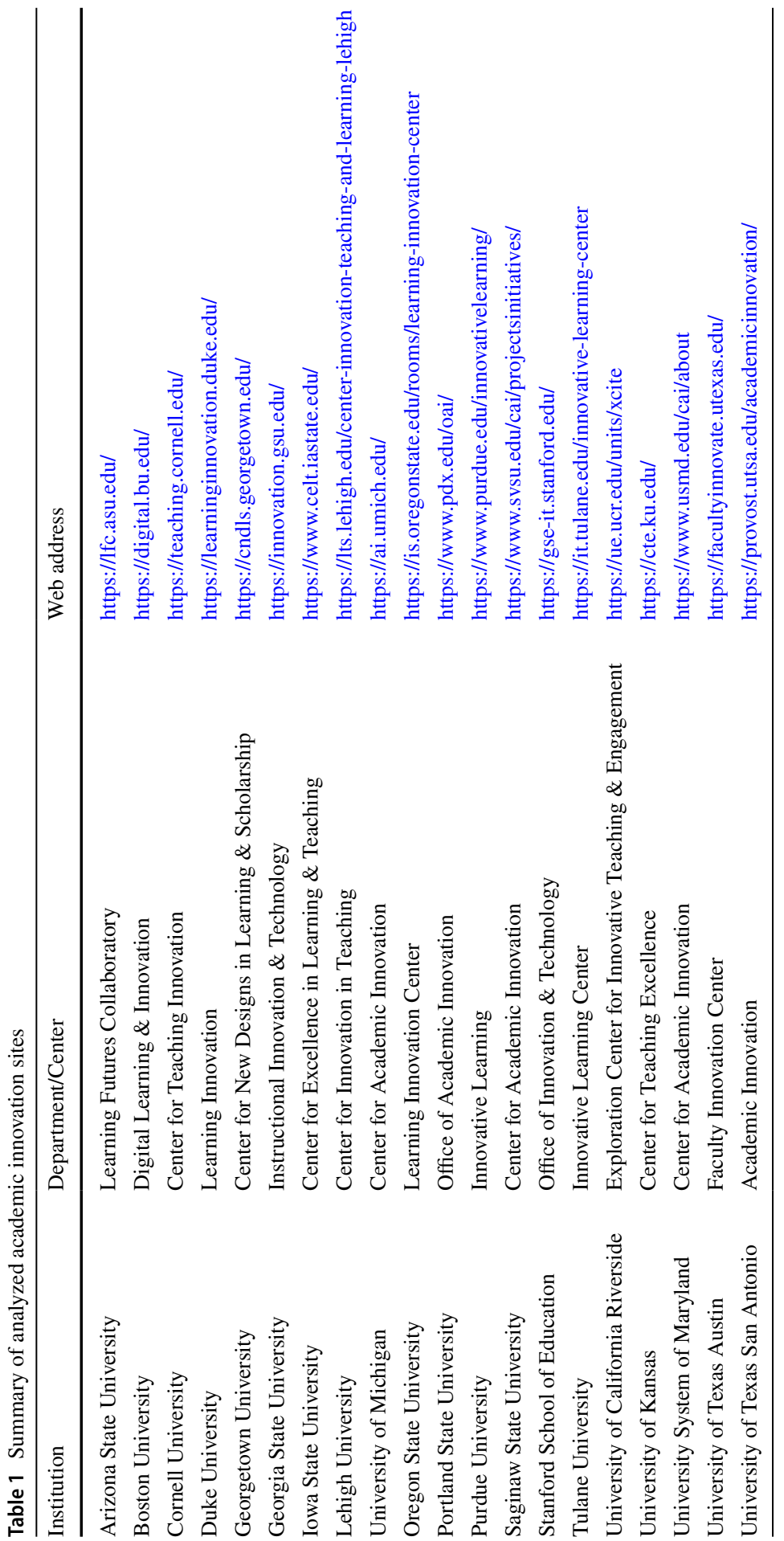




\section{Findings}

Through the analysis of 20 college and university academic innovation websites, we observed the broad scope of interpretation of the term academic innovation. Because our analysis focused on one click-level from the main webpage, there was certainly additional detail that could have been provided from further investigation. However, this methodology provided content that was most easily accessible to site visitors. We aligned the themes that emerged from this unit of analysis to the aforementioned three categories: educational technology, evaluation, and connections. These categories became our parent codes during the analysis phase, and several child codes emerged through the process as well (see Table 2).

\section{Educational Technology}

The term academic innovation lends itself to an obvious connection to educational technology. However, through the coding process, two types of educational technology emerged. These informed the child codes of digital spaces and physical spaces. Educational Technology was the third most coded (274) with the highest within digital spaces (177). Some HEIs invested funds to create physical spaces such as innovation centers or modern classroom settings that created flexible learning environments through the use of technology. More often, however, was the use of digital spaces for educational technology. These included online learning environments, support for learning management systems, and digital communication tools. Further analysis led to investigating where educational technology was pedagogical. We noted child codes of teacher-centered and student-centered. Pedagogical was the most coded (475) with

Table 2 Code frequency

\begin{tabular}{ll}
\hline Pedagogical & 475 \\
Connections & 290 \\
Ed Tech & 274 \\
Pedagogy: Teacher-centered & 260 \\
Ed Tech: digital spaces & 177 \\
Connections: online/tech & 124 \\
Standards of evaluation & 105 \\
Non-pedagogical & 78 \\
In-person connections & 68 \\
Evaluation: student learning & 56 \\
Pedagogy: student-centered & 46 \\
Images: technology interactions & 42 \\
Images: human interactions & 37 \\
Ed Tech: physical spaces & 27 \\
Evaluation: teacher effectiveness & 21 \\
Buzz words & 19 \\
Imagery & 19 \\
Evaluation: Program success & 19 \\
Images: Innovation & 13 \\
\hline
\end{tabular}


the highest frequency in teacher-centered (260). The majority of sites focused on technology in course design to engage students in online and physical spaces. Sites often highlighted support for faculty in learning management tools, application creation, and the use of digital tools to enhance instruction through online learning modules, in-person workshops, and financial support such as grants or other funding sources. There was a strong presence of pedagogical tools for faculty, yet little evidence of mechanisms in place to assess the tools' ability to improve instruction.

\section{Standards of Evaluation}

This content analysis included examining the degree to which programs assess and evaluate their success to improve student achievement. Standards of evaluation was a parent code (105) with two disparate child codes that emerged. The most common was the child code student learning (56) which tended to address assessment and evaluation of student learning through a variety of flexible and often adaptive technologies. The other child code that emerged, although present in fewer sites, was program success (19). Program success codes indicated a clear process by which they evaluated their academic innovation efforts and to what degree they were successful. Academic innovation success indicators often highlight aspects of student learning. For example, faculty support for creating student assessments (through learning management system tools) and support for student use of online tools/ resources illustrated paths for academic innovation in support of student learning.

As an additional avenue to explore standards of evaluation, we took a closer look at whether or not mission statements were accessible within a one-click level on the websites. These statements often address a vision or goal to be evaluated in the future. We noted mission statements were rarely stated explicitly. There are a few examples where a mission or vision was referenced indirectly with a statement of purpose for academic innovation that included items on improving student achievement, supporting underrepresented groups, or a focus on STEM initiatives. Although mission statements were not clearly defined within our one-click level of analysis, it is evident that all sites acknowledged the importance of making connections to internal and external resources to support their endeavors.

\section{Community Connections}

Community connections were a clear thread present in all sites. The parent code of connections had the second-highest codes (290). The child codes that emerged were onlinel technology (124) and in-person connections (68). Community connections were most often leveraged through in-person programming for internal audiences through workshops to connect faculty, events for the college community-at-large, or experiential learning opportunities for students. Furthermore, academic innovation units often collaborated with other university units through hyperlinks to entities such as information technology, libraries, and other research groups. These connections provided faculty support in the form of consultations, technology support, instructional design, and student support in areas of research, writing, and the use of technology. There were few sites that made an effort to highlight global communication initiatives and tools on their introductory pages. 
Finally, we observed repositories of additional resources for both faculty and students in the form of blogs, newsletters, podcasts, and publications highlighted on these sites.

In addition to the data collected through coding, some interesting memos emerged throughout the analysis. For example, the amount of personnel support dedicated to academic innovation varied greatly. We observed a variation in academic innovation staffing numbers ranging from 3-50 staff members. In some cases, there were graduate students or external contractors indicated as part of the team. The varied level of personnel investment likely influences both the communication and institutional commitment to innovation efforts. Another code that emerged, but did not lead to an overall theme, was buzz words. Often used yet seldom defined terminology throughout the sites indicate some aspects of varied purpose among HEI academic innovation efforts. Examples included: Chief Innovation Officer, instructional innovation, digital scholarship, digital engagement collaborative, instructional continuity, digital initiatives, fluency, innovation workstream, and innovation collaboratory. The variety of words indicated here showcases the highly contextualized nature of academic innovation as well as the lack of specificity of efforts and varied levels of success addressed through the websites we examined.

\section{Levels of Innovation}

This study sought to illuminate the potential programmatic and communication commonalities, discrepancies, and challenges across 20 institutions' academic innovation websites. Consistent foci such as educational technology and enhanced pedagogy cut across most institutions in our sample, yet each institution maintains unique approaches to academic innovation that stem from context-specific realties such as resources, stakeholder buy-in, and internal collaboration. A useful construct for interpreting the commonalities and differences across institutions is Serdyukov's (2017) levels of innovation impact. This spectrum indicates three levels describing the potential scope and impact of academic innovations: (1) adjustment or upgrading of the process, (2) modification of the process, or (3) transformation of the system. These levels are not evaluative in terms of success or progression. Rather, they indicate characteristics of innovation in terms of intent and degree of impact. Table 3 summarizes sample data and plots institutions' level of innovation, as determined by our synthesis of data, based on the following descriptions from Serdyukov (emphasis added):

Adjustment or upgrading of the process: innovation can occur in daily performance and be seen as a way to make our job easier, more effective, more appealing, or less stressful. This kind of innovation, however, should be considered an improvement rather than innovation because it does not produce a new method or tool.

Modification of the process: innovation that significantly alters the process, performance, or quality of an existing product ...

Transformation of the system: dramatic conversion (e.g. ... fully automated educational systems; autonomous or self-directed learning; online, networked, and mobile learning) (p. 8). 
Table 3 Level of Innovation

\begin{tabular}{|c|c|c|}
\hline $\begin{array}{l}\text { Most frequent codes in HEI } \\
\text { webpage }\end{array}$ & Site content highlights & Level of innovation impact \\
\hline $\begin{array}{l}\text { digital spaces }(27) \text { online/ } \\
\text { tech connection }(18) \text { tech } \\
\text { interaction images }(17)\end{array}$ & $\begin{array}{l}\text { Experiential,Inclusive, interactive learn- } \\
\text { ing, flipped classrooms, AR, VR, XR }\end{array}$ & modification \\
\hline $\begin{array}{l}\text { connections (15)ed tech (16) } \\
\text { pedagogical (11) }\end{array}$ & $\begin{array}{l}\text { innovation collaboratory,focus on digital } \\
\text { fluency,digital credentialing,universal } \\
\text { learning, personalized campusexperi- } \\
\text { ences for learners }\end{array}$ & modification/transformation \\
\hline $\begin{array}{l}\text { online/tech (13) digital } \\
\text { spaces (11)teacher-cen- } \\
\text { tered (9) }\end{array}$ & $\begin{array}{l}\text { support for transforming learning, } \\
\text { tech toolssupport for staff,funding } \\
\text { opportunities, online learning,building } \\
\text { community }\end{array}$ & modification \\
\hline $\begin{array}{l}\text { teacher-centered (10)human } \\
\text { interactions (8)in-person } \\
\text { connection (7) }\end{array}$ & $\begin{array}{l}\text { deliver course content, online } \\
\text { learning,workshops, collaboration, } \\
\text { inclusive classrooms, active learning }\end{array}$ & adjustment \\
\hline $\begin{array}{l}\text { pedagogical }(68) \text { teacher- } \\
\text { centered (38)connections } \\
(28)\end{array}$ & $\begin{array}{l}\text { online learning tools, working remotely, } \\
\text { training/support, inclusive pedagogy, } \\
\text { assessment/evaluation }\end{array}$ & adjustment/modification \\
\hline $\begin{array}{l}\text { online/technological (8)ed } \\
\text { tech (6) student-centered } \\
(6)\end{array}$ & $\begin{array}{l}\text { digital learners to leaders, experiential } \\
\text { learning, innovative instruction, digital } \\
\text { literacy initiative, cyberinfrastructure } \\
\text { plan }\end{array}$ & modification \\
\hline $\begin{array}{l}\text { pedagogical (7)eval student } \\
\text { learning (6)ed tech }(5)\end{array}$ & $\begin{array}{l}\text { instructional continuity,technology } \\
\text { assessmentresearch, partnering with } \\
\text { EdX, technology-enhanced learning }\end{array}$ & adjustment/modification \\
\hline Most frequent codes & Site content highlights & Level of innovation impact \\
\hline $\begin{array}{l}\text { online/technological (7) } \\
\text { digital spaces (5) images of } \\
\text { technology interactions (7) }\end{array}$ & $\begin{array}{l}\text { digital scholarship, classroom technology } \\
\text { support,learning space design,virtual } \\
\text { desktops, experiential learning }\end{array}$ & modification \\
\hline $\begin{array}{l}\text { connections (32)ed tech } \\
\text { (21)non-pedagogical (21) } \\
\text { pedagogical (25) }\end{array}$ & $\begin{array}{l}\text { The Hub (physical space), digital } \\
\text { learning,video production, lab,HUB } \\
\text { cast podcast }\end{array}$ & modification \\
\hline $\begin{array}{l}\text { connections (10)ed tech (10) } \\
\text { pedagogical (11) }\end{array}$ & $\begin{array}{l}\text { architects design, learning innova- } \\
\text { tion center for new learning,ed } \\
\text { tech,technology enhanced physical } \\
\text { spaces,support for staff }\end{array}$ & modification \\
\hline $\begin{array}{l}\text { connections (29)ed tech }(30) \\
\text { pedagogical (48) }\end{array}$ & $\begin{array}{l}\text { significant changes create online and } \\
\text { experiential learning opportunities }\end{array}$ & modification \\
\hline $\begin{array}{l}\text { pedagogical (23)ed tech (13) } \\
\text { connections (10) }\end{array}$ & $\begin{array}{l}\text { shifting to online learning opportunities- } \\
\text { support for faculty }\end{array}$ & modification \\
\hline $\begin{array}{l}\text { pedagogical (35)ed tech }(30) \\
\text { connections }(27) \text { teacher- } \\
\text { centered (27) }\end{array}$ & $\begin{array}{l}\text { supporting instruction,engaging students, } \\
\text { global learning, accessibility,faculty } \\
\text { support, creating content }\end{array}$ & adjustment \\
\hline $\begin{array}{l}\text { online/technological (8) } \\
\text { non-pedagogical (8)digital } \\
\text { spaces }(6)\end{array}$ & $\begin{array}{l}\text { chat bots,mobile inquiry-based learning } \\
\text { environment, app development, simula- } \\
\text { tions, conversational AI }\end{array}$ & modification/transformation \\
\hline
\end{tabular}


Table 3 (continued)

\begin{tabular}{|c|c|c|}
\hline $\begin{array}{l}\text { Most frequent codes in HEI } \\
\text { webpage }\end{array}$ & Site content highlights & Level of innovation impact \\
\hline $\begin{array}{l}\text { connections (19) pedagogical } \\
\text { (19) student-centered (9) }\end{array}$ & $\begin{array}{l}\text { swift transition to online learning, virtual } \\
\text { chats, experiential learning, collabo- } \\
\text { ration with the community,tutoring, } \\
\text { research, engagement,[collaboration] } \\
\text { facility }\end{array}$ & adjustment \\
\hline $\begin{array}{l}\text { ed tech (6) connections }(5) \\
\text { digital spaces }(5) \text { teacher- } \\
\text { centered (5) }\end{array}$ & $\begin{array}{l}\text { liaisons between IT and research,new } \\
\text { tactics for lessons, workshops,tech tools }\end{array}$ & adjustment \\
\hline $\begin{array}{l}\text { pedagogical (32)teacher- } \\
\text { centered (22)ed tech }(7)\end{array}$ & $\begin{array}{l}\text { making learning accessible,inclusive syl- } \\
\text { labus, using technology, online classes, } \\
\text { professional development }\end{array}$ & adjustment \\
\hline $\begin{array}{l}\text { connections (5)pedagogical } \\
\text { (5)standards of evalua- } \\
\text { tion (7) }\end{array}$ & $\begin{array}{l}\text { removing barriers, accessibility, } \\
\text { affordability,quality,academic innova- } \\
\text { tion to support student success, high } \\
\text { impact practices }\end{array}$ & modification \\
\hline $\begin{array}{l}\text { Pedagogical (36)Ed Tech } \\
\text { (30)digital spaces (17) }\end{array}$ & $\begin{array}{l}\text { classroom technology support,digital } \\
\text { experience lab, production services } \\
\text { for online/hybrid courses,immersive } \\
\text { learning }\end{array}$ & adjustment/modification \\
\hline $\begin{array}{l}\text { Pedagogical (109) Teacher- } \\
\text { centered (99) Connections } \\
(46)\end{array}$ & $\begin{array}{l}\text { inclusive teaching and } \\
\text { learning,instructional continuity,remote } \\
\text { teaching tools,graphic syllabus,flipped } \\
\text { classroom, democratization of the } \\
\text { classroom,faculty innovation center }\end{array}$ & adjustment/modification \\
\hline
\end{tabular}

Table 3 illustrates the potential degree of innovation impact based solely on the unitized and coded data for this study. It is possible that other aspects of academic innovation are captured or communicated differently throughout institutions' websites. As a result, Table 3 is illustrative of potential academic innovation, planning, and evaluation structures, and is not evaluative of holistic institution efforts.

\section{Discussion}

The findings and summary of innovation impact underscore two primary elements of academic innovation that warrant discussion and further exploration. First, demonstrated effort in academic innovation may or may not align with realized efficacy. Secondly, institutional websites as an aspect of academic innovation communication present opportunities for more consistent internal and forward-facing communication. Our discussion illuminates commonalities in institutional contexts and innovation processes, though our scope and analysis methods may limit the generalizability and transferability of some elements. 


\section{Effort versus Efficacy}

Most HEIs in this study make efforts toward new or novel ideas but do not significantly address realized change or efficacy. This may be partly because they exist in liminal spaces between various degrees of impact as noted in Table 3. Additionally, upfront investments of time and resources do not always align with perceived success, or effectiveness, of academic innovation initiatives. Efficacy seems to be interrelated with how well stakeholders expectations are managed and how, if at all, innovation benefits are communicated to end users (often faculty). This assertion aligns with Whitworth's (2011) evaluation of grand educational technology innovations and Findlow's (2008) call for transparency and trust throughout the innovation process.

Findings of the present study suggest that transparency and alignment of goals and outcomes better situate HEIs to move towards innovations that modify and/or transform institutional systems and culture. For example, exploring how, if at all, an institution navigates using existing resources and collaborations around educational technology provides more specific connections to what change in capacity is possible through a new innovation initiative. Closer examination of what efficacy looks like and how success is evaluated should include indicators addressing consistent standards for exploring or initiating innovation opportunities and how best to communicate these opportunities to the larger community.

\section{Intentional Communication}

HEIs in this study all make some level of effort to communicate both their goals and current activities or initiatives via a public-facing website. Though they vary in specificity, websites tend to be an important aspect of HEI communication and engagement with internal and external stakeholders. Our findings suggest that a greater degree of intentionality regarding academic innovation purposes and processes could aid in communicating clear benefits to all stakeholders. Similar to Dobbins (2009), we suggest contextualizing potential advantages of academic innovation is helped by personalizing opportunities and motivating stakeholders to engage. Accordingly, HEI academic innovation units might recruit and maintain interest from stakeholders through more reflexive and consistent communication and messaging regarding how innovation helps or improves individual workflows.

Intentional communication could entail systematic assessment of activities, clear definitions of industry terms, and specific links between academic innovation initiatives and stated mission goals or values. For example, some of the HEIs in this study adopted innovation buzzwords without clearly defining them or providing scholarly context. Though using current terminology is a natural tendency, HEIs could benefit from clear and consistent terminology that reinforces unit goals and better translates current and potential impact in the larger field of academic innovation. 


\section{Application and Conclusion}

This study examined academic innovation websites to better understand the link between innovation and educational technology, approaches to academic innovation success indicators, and relevant stakeholder communities. Academic innovation as a concentrated or distinct effort in HEIs is increasingly common as universities seek to maintain currency and effectiveness in a competitive educational space. However, the structure and communication of academic innovation units do not present a common understanding or mission for innovation in higher education broadly. Instead, most academic innovation units reviewed in this study form their own approaches for navigating new initiatives and determining success. Opportunities exist for HEIs to more clearly communicate and showcase their academic innovations as contributions to the larger higher education community. Emphasizing clear goals for academic innovation efforts, understanding intended level of innovation impact, and transparent communication of accomplishments will ultimately help institutions move towards transformative educational systems. More specific efforts in these areas can enable HEIs to systematize and standardize academic innovation within their context as well as contribute to innovative solutions in higher education broadly. This call to action for greater transparency and specific attention to innovation outcomes will strengthen institutions' program efficacy as well as their approach to online communication via websites.

This article contributes to a growing literature base on academic innovation as an integrated process and aspirational goal. Despite the natural limitations of content analysis methods for exploring point-in-time hypertext, we hope this article serves as a point of reflection as well as an insight to measuring current and potential opportunities for academic innovation impact. Many questions remain in terms of how forward-facing communication, such as websites, can both fuel and communicate academic innovation that applies new or novel ideas in evolving learning environments. This study highlighted the profound differences in HEI contexts and the forward-facing communication that signals how academic innovation is structured. Further research on individual stakeholder roles, institutional commitment and funding, and internal collaboration will help illuminate more specific pathways for plotting innovation as a distinct effort beyond technology integration or short-lived projects. Opportunities for multi-institution collaboration and sharing of information across academic innovation efforts, such as a virtual summit or special interest research group, could provide clarity and vision in the field. In doing so, HEIs can make the potentially invisible successes of academic innovation (Whitworth, 2011) a more tangible experience and realized change.

Funding This research was supported by The Studio for Teaching \& Learning Innovation at William \& Mary in Williamsburg, VA.

Data Availability All data and material for this study are publically available websites and associated content as noted within the article. 


\section{Declarations}

Conflicts of interests We have no conflicts of interest to disclose.

\section{References}

Barger, A. P. (2016). Teachers' perceptions of contextual influences on instructional decision-making regarding the use of educational technology in secondary social studies (Publication No. 10161496). [Doctoral dissertation, The College of William and Mary]. ProQuest Dissertations \& Theses Global.

Blumenstyk, G. \& Gardner, L. (2019). Innovation imperative: The buzz, the barriers, and what real change looks like. The Chronicle of Higher Education.

Cervero, R., \& Wilson, A. (1998). Working the planning table: The political practice of adult Education. Jossey-Bass. https://doi.org/10.1080/0158037980200101

Dobbins, K. (2009). Feeding innovation with Learning Lunches: Contextualising academic innovation in higher education. Journal of Further and Higher Education, 33(4), 411-422. https://doi.org/10. 1080/03098770903272495

Findlow, S. (2008). Accountability and innovation in higher education: A disabling tension? Studies in Higher Education, 33(3), 313-329. https://doi.org/10.1080/03075070802049285

Hoffman, A. \& Holzhuter, J. (2012). The evolution of higher education: Innovation as natural selection. In A. Hoffman \& S. Spangehl (Eds.), Innovation in higher education: Igniting the spark for success (pp. 3-15). American Council on Education, Rowman \& Littlefield Publishers Inc.

Jakovljevic, M. (2018). A model for innovation in higher education. South African Journal of Higher Education, 32(4), 109-132. https://doi.org/10.20853/32-4-2432

Kezar, A. (2011). What is the best way to achieve broader reach of improved practices in higher education? Innovative Higher Education, 36(4), 235-247. https://doi.org/10.1007/s10755-011-9174-z

Kezar, A., Gehrke, S., \& Bernstein-Sierra, S. (2018). Communities of transformation: Creating changes to deeply entrenched issues. Journal of Higher Education, 89(6), 832-864. https://doi.org/10.1080/ 00221546.2018 .1441108

Kim, I., \& Kuljis, J. (2010). Applying content analysis to web-based content. Journal of Computing and Information Technology, 18(4), 369-375. https://doi.org/10.2498/cit.1001924

King, E., \& Boyatt, R. (2014). Exploring factors that influence adoption of e-learning within higher education. British Journal of Educational Technology, 46(6), 1272-1280. https://doi.org/10.1111/bjet. 12195

Krippendorff, K. H. (2013). Content analysis - (3rd ed.). SAGE Publications Inc.

Lindquist, J. (1974). Political linkage: The academic-innovation process. The Journal of Higher Education, 45(5), 323-343. https://doi.org/10.2307/1980380

McClure, K. R. (2015). Exploring curricular transformation to promote innovation and entrepreneurship: An institutional case study. Innovative Higher Education, 40, 429-442. https://doi.org/10.1007/ s10755-015-9325-8

McMillan, S. J. (2000). The microscope and the moving target: The challenge of applying content analysis to the World Wide Web. Journalism and Mass Communication Quarterly, 77(1), 80-98. https:// doi.org/10.1177/107769900007700107

Orton, J. D., \& Weick, K. E. (1990). Loosely coupled systems: A reconceptualization. Academy of Management the Academy of Management Review, 15(2), 203. https://doi.org/10.2307/258154

Palinkas, L. A., Horwitz, S. M., Green, C. A., Wisdom, J. P., Duan, N., \& Hoagwood, K. (2015). Purposeful sampling for qualitative data collection and analysis in mixed method implementation research. Administration and Policy in Mental Health and Mental Health Services Research, 42(5), 533-544. https://doi.org/10.1007/s10488-013-0528-y

Papert, S. (1987). Information technology and education: Computer criticism vs. technocentric thinking. Educational Researcher, 16(1), 22-30. https://doi.org/10.3102/0013189X016001022

Papert, S. (1988). A critique of technocentrism in thinking about the school of the future. Children in the Information Age, 3-18. https://doi.org/10.1016/B978-0-08-036464-3.50006-5

Patton, M. Q. (2002). Qualitative research and evaluation methods (3rd ed.). Sage. 
Serdyukov, P. (2017). Innovation in education: What works, what doesn't, and what to do about it? Journal of Research in Innovative Teaching \& Learning, 10(1), 4-33. https://doi.org/10.1108/ jrit-10-2016-0007

Song, L., Tso, G., \& Fu, Y. (2019). Click behavior and link prioritization: Multiple demand theory application for web improvement. Journal of the Association Society for Information Science and Technology, 70(8), 805-816. https://doi.org/10.1002/asi

Stvilia, B., \& Gibradze, L. (2019). Exploring Twitter use and services of academic innovation centers. The Journal of Academic Librarianship, 45(5), 102052. https://doi.org/10.1016/j.acalib.2019. 102052

Suri, H. (2011). Purposeful sampling in qualitative research synthesis. Qualitative Research Journal, 11(2), 63-75. https://doi.org/10.3316/QRJ1102063

Tierney, W. G., \& Lanford, M. (2016). Conceptualizing innovation in higher education. In M. Paulsen (Ed.), Higher education: Handbook of theory and research (pp. 1-40). Springer. https://doi.org/10. 1007/978-3-319-26829-3_1

Walder, A. M. (2017). Pedagogical innovation in Canadian higher education: Professors' perspectives on its effects on teaching and learning. Studies in Educational Evaluation, 54, 71-82. https://doi.org/ 10.1016/j.stueduc.2016.11.001

Weick, K. E. (1976). Educational organizations as loosely coupled systems. Administrative Science Quarterly, 21(1), 1-19. https://doi.org/10.2307/2391875

Whitworth, A. (2011). Invisible success: Problems with the grand technological innovation in higher education. Computers and Education, 59(1), 145-155. https://doi.org/10.1016/j.compedu.2011.09.023

Publisher's Note Springer Nature remains neutral with regard to jurisdictional claims in published maps and institutional affiliations.

Adam P. Barger, Ph.D is the Associate Director for Academic Innovation in the William \& Mary Studio for Teaching \& Learning Innovation. His teaching and research focus on educational technology and innovation, digital fluency in teaching and learning, web-based pedagogy, and multimodal assessments.

Kelly Govain Leffel is a doctoral student in the Curriculum \& Learning Design program in the William \& Mary School of Education. Currently, her research focuses on educational technology and professional development.

Mia Lott is a 2020 alumna of William \& Mary. 